\title{
An Experimental Study to Assess the Professional and Social Consequences of Tardive Dyskinesia
}

\author{
Rajeev Ayyagari ${ }^{1}$, Debbie Goldschmidt', Fan Mu', Stanley N. Caroff ${ }^{2,3}$, Benjamin Carroll ${ }^{4}$ \\ ${ }^{1}$ Analysis Group, Inc., Boston, MA, ${ }^{2}$ Corporal Michael J. Crescenz VA Medical Center, Philadelphia, PA, ${ }^{3}$ Department of Psychiatry, \\ University of Pennsylvania Perelman School of Medicine, Philadelphia, PA, ${ }^{4}$ Teva Pharmaceuticals, West Chester, PA, USA
}

\begin{abstract}
Objective: Antipsychotic medications may cause tardive dyskinesia (TD), an often-irreversible movement disorder characterized by involuntary movements that are typically stereotypic, choreiform, or dystonic and may impair quality of life. This study evaluated others' perceptions of abnormal TD movements in professional and social situations.

Methods: This was an experimental, randomized, blinded, digital survey in a general population sample. Participants were randomized 1:1 into a test or control group to view a video of a professional actor simulating TD movements or no TD movements prior to completing surveys on employment, dating, and friendship domains. Assessments for mild-to-moderate and moderate-to-severe TD movements were conducted separately. Authenticity of abnormal movements and Abnormal Involuntary Movement Scale (AIMS) scores were evaluated by physician experts.

Results: Surveys were completed by 2,400 participants each for mild-to-moderate and moderate-to-severe TD. In all domains, participants responded significantly less favorably to persons with TD movements (both mild-to-moderate and moderate-to-severe) than those without TD movements. Fewer participants in the test versus control group for mild-to-moderate and moderate-to-severe TD, respectively, considered the candidate as a potential employee $(29.2 \%$ and $22.7 \%$ fewer), found him/her attractive $(20.5 \%$ and $18.7 \%$ fewer), and were interested in becoming friends with him/her (12.3\% and $16.5 \%$ fewer).

Conclusion: Professional actors simulating TD movements were perceived more negatively than those without TD movements in employment, dating, and friendship domains. To our knowledge, this is the first randomized study to quantify professional and social stigma associated with TD movements that may reduce opportunities for gainful employment, marital status, and an effective support system.
\end{abstract}

KEY WORDS: Tardive dyskinesia; Social stigma; Antipsychotics; Movement disorders.

\section{INTRODUCTION}

Antipsychotic medications are first-line treatments for schizophrenia, and some agents that have been approved for mood disorders are increasingly being used to treat bipolar disorder and major depressive disorder [1-3]. Despite their efficacy, antipsychotic medications can cause side effects that may impact quality of life, patient function, medication tolerability, and compliance with treatment, thereby increasing the risk of relapse $[4,5]$.

A serious side effect that can emerge from exposure to

Received: June 11, 2021 / Accepted: July 12, 2021

Address for correspondence: Rajeev Ayyagari

Analysis Group, Inc., 111 Huntington Avenue, Fourteenth Floor, Boston, MA 02199, USA

E-mail: rajeev.ayyagari@analysisgroup.com

ORCID: https://orcid.org/0000-0003-0870-2309 antipsychotics is tardive dyskinesia (TD), an often-irreversible hyperkinetic movement disorder [6,7]. TD is prevalent among $20 \%$ to $30 \%$ of patients on long-term antipsychotics, and its prevalence may increase due to aggressive marketing, expanded indications, and off-label use of antipsychotics in a broader patient population [2,3,8-11]. Characteristics include a range of involuntary, hyperkinetic movements that are typically stereotypic, choreiform, or dystonic and most often affect the orofacial region $[5,10,12,13]$.

The social and emotional impact of TD movements are not well understood. In the past, the awareness, distress, and significance of TD in terms of quality of life have been underestimated due to poor-quality investigations in nonrepresentative samples of people with TD. People studied usually had chronic mental illnesses, were confined to an

(c) This is an Open-Access article distributed under the terms of the Creative Commons Attribution Non-Commercial License (http://creativecommons.org/licenses/by-nc/4.0) which permits unrestricted non-commercial use, distribution, and reproduction in any medium, provided the original work is properly cited. 
institutional setting, and were often unable to recognize TD due to cognitive and sensory impairment [14-16]. Although some patients may not be fully aware of having TD, abnormal movements may nevertheless affect other people who may observe them and stigmatize the patient. The appearance of odd postures and movements may invite ridicule, bullying, and ostracism from observers and induce shame, withdrawal, and isolation in affected individuals. Several studies have shown correlations between TD and impaired cognition, poor response to treatment, greater risk of relapse, longer hospital stays, increased health care resource utilization, and lower quality of life and functioning [15,17-23]. These correlations are often confounded by the concurrent effect of serious underlying psychiatric illnesses of the people in these studies. The severity of these conditions may contribute to the risk of TD due to aggressive treatment with antipsychotics as well as to poor social and clinical outcomes. Development of antipsychotic-induced abnormal movements can only add to the burden and stigma of having a mental illness.

Assessing the impact of TD movements on personal psychologic and social stigmas has proven to be difficult and has thus received limited attention. A key challenge is that standard movement severity ratings or the simple concrete items on awareness and incapacitation used in clinical trials (such as the Abnormal Involuntary Movement Scale [AIMS]) may not adequately capture the impact of TD related to social stigma [24]. It also has been difficult to differentiate the stigma of TD from that of symptoms associated with an underlying mental illness. Apart from patient and clinician assessments, the reaction by lay observers to abnormal movements exhibited in public social situations and its impact on patient lives have not received adequate attention.

People with TD have described its social and emotional impact as the most debilitating aspects of living with the condition [25]. Even mild, involuntary movements in the facial area can cause difficulty in social interactions and in attaining or maintaining employment [25]. However, clinicians may not recognize the impact of mild-to-moderate TD, assuming that such symptoms are acceptable to the patient and are not noticeable to others. As a result, these assumptions may lead to a delay in diagnosis or treatment of these cases. However, there remains a need to understand how the severity of TD movements (e.g., mild-to-moderate or moderate-to-severe) contributes to the perceptions people have when observing or interacting with individuals with TD.

Despite the growing prevalence of TD [26] and the expanded use of antipsychotics in a broader segment of the population, to our knowledge, only 1 experimental study published more than 25 years ago has evaluated the social consequences of TD in a job application scenario. However, methodologic shortcomings in the study design, including not using videos for the control group, small sample size, and differences other than the presence of orofacial TD movements in the videos, limit the interpretation of results $[9,27]$.

The goal of the current study was to quantify the stigma of abnormal TD movements in both mild-to-moderate and moderate-to-severe cases in a variety of professional and social situations using a new methodology that limited confounding factors associated with differences between test and control groups.

\section{METHODS}

\section{Overview}

This randomized, digitally administered survey study used a 1-time data collection from a sample of the general population in the United States. A targeted literature review was first performed to examine existing evidence on the impact of TD symptoms on patients' professional or social life. One-on-one phone interviews were then conducted with patients to learn about their experience with TD. Information collected from the targeted literature review and patient interviews was used to guide the development of surveys that were administered to members of the general population. Three surveys were developed, one for each domain (employment, dating, and friendship). Domain-specific screening criteria were applied (e.g., participants to the employment survey were required to have hiring/interviewing experience, participants to the dating survey were required to be single and open to online/blind dates in the next 6 months). Separate samples of participants were used to compare survey responses for people with or without either mild-to-moderate or moderate-to-severe TD movements, with no overlap between groups or surveys. 


\section{Survey Participants}

Survey participants ( $\geq 20$ years of age for mild-to-moderate TD and $\geq 18$ years of age for moderate-to-severe TD and able to speak and read English) from the general US population were recruited (mild-to-moderate TD, 4/4/2019-5/10/2019; moderate-to-severe TD, 12/3/2018$1 / 10 / 2019$ ) through a panel that was maintained by a well-established global provider of data collection and market research. Participants were invited to participate via email and received a small incentive payment for completing the survey. Participants were asked to review an informed consent form outlining the benefits and risks of the study and to confirm they were willing to participate before they could begin the survey. Raw data from all participants and records of the consent were retained.

\section{Ethics Approval and Consent to Participate}

The New England Institutional Review Board approved the study for moderate-to-severe TD on November 21, 2018 and mild-to-moderate TD on April 23, 2019 (no approval numbers available). All survey participants and patients with TD were required to provide informed consent.

\section{Study Design}

Participants were asked to watch a standardized video of a person speaking from a short script. Four professional actors (a young man [age 25 - 30 years], a young woman [age 25 - 30 years], an older man [age $40-45$ years], and an older woman [age 40-45 years]) performed the following scenarios. In the employment domain, the person introduced him/herself as a candidate at a job interview. In the dating domain, the person briefly introduced him/ herself to a potential date met on a dating application. In the friendship domain, the person asked a friend of a friend for advice about moving to the survey participant's city.

Each scenario had 2 versions in which professional actors either simulated someone with or without orofacial TD movements, with the script, setting, and all other aspects (e.g., actor position, dress and appearance, speech, lighting, background and surroundings, background noise level, and camera angles) remaining similar. Abnormal TD movements simulated by professional actors were rehearsed with coaching by an expert on TD to achieve a total score on the AIMS (sum of items $1-7$ ) between 3 and 6 for mild-to-moderate TD movements and between 6 and 10 for moderate-to-severe TD movements [28,29]. Each video was subsequently evaluated for authenticity of the simulated abnormal TD movements by a panel of 3 physicians (total of 6 physicians) for mild-to-moderate TD and 2 or 3 physicians (total of 5 physicians) for moderate-to-severe TD. All participating physicians specialized in psychiatry (or neurology for the mild-to-moderate group), had experience treating patients with TD, and used AIMS in their practices. The authenticity of TD movements was evaluated on a scale of 0 to 4 ( $0=$ the actor's TD symptoms are very unrealistic; $1=$ the actor's TD symptoms are moderately unrealistic; $2=$ the actor's TD symptoms are realistic; 3 = the actor's TD symptoms are very realistic; $4=$ the actor's TD symptoms are almost indistinguishable from those of a real-life person with TD). The mean \pm standard deviation physician-rated authenticity scores of mild-to-moderate TD symptoms in the employment, dating, and friendship videos were $2.5 \pm 0.7,2.5 \pm$ 0.7 , and $2.6 \pm 0.7$, respectively; and authenticity scores of moderate-to-severe TD symptoms were $2.9 \pm 0.9,3.1 \pm$ 0.7 , and $3.1 \pm 0.8$, respectively (Supplementary Table 1; available online).

Apart from simulated mild-to-moderate or moderateto-severe TD movements, people portraying TD patients did not exhibit any signs of mental illness in their affect, behavior, or scripted monologue, thus eliminating any confounding effects apart from abnormal movements on assessments of social and occupational suitability. Participants' perceptions of TD simulated by professional actors and the differences between the test and control groups were assessed after they watched the videos.

For each domain, participants were randomized 1:1 to watch either the video with TD movements (test) or the video without TD movements (control). While participants were randomly assigned to 1 of the 4 professional actors in the employment domain, participants in the dating and friendship domains were assigned a video that matched their age and sexual orientation (e.g., participants in the dating domain who were 30 years of age or younger and interested in dating men were shown a video performed by a young man, while participants who were 40 years of age or older and interested in dating men were shown a video performed by an older man; participants aged $31-39$ years were randomly assigned to the younger or older group). Confounding of survey results due to respondent or professional actor characteristics was con- 
trolled for by randomization and use of the same professional actor for the video with or without TD movements.

\section{Survey Instruments}

Three separate surveys for employment, dating, and friendship domains were developed based on a targeted literature review that identified existing research methodologies measuring the professional and social impact of abnormal facial features. To further guide the development of surveys, phone interviews were conducted with patients who had a TD diagnosis and experienced TD symptoms (both confirmed during the interview), were 18 to 65 years of age, spoke English fluently, did not primarily receive inpatient care, and were willing to discuss their experiences living with TD, particularly within the domains of employment, dating, and friendship. All interviewed patients reported having some degree of anxiety or embarrassment about their TD movements, especially in professional settings or when meeting new people. All patients described a common feeling that others were anxious or uncomfortable in their presence.

For the surveys of the general population, each participant was given only 1 survey that collected their demographic characteristics and socioeconomic status, as well as domain-specific information. The survey for the employment domain included questions about participants' employment status, work experience, and interviewing/ hiring experience. The survey for the dating domain contained additional questions about participants' past dating experience, and the survey for the friendship domain had questions about participants' sociability. Subsequently, the participants viewed a video (audio/visual) relevant to their survey and completed a questionnaire about their perception of the professional actor in the video. They were asked to rate their level of agreement with specific statements regarding the professional actors' qualifications for employment, attractiveness relevant to dating, and friendship on a 5-point Likert scale (from "strongly agree" to "strongly disagree"). To blind and conceal the purpose of the survey, the questionnaire for each domain included 2 questions that were unrelated to the study objectives, such as asking about the professional actor's hairstyle or clothing.

\section{Statistical Methods}

Participant characteristics and responses regarding their perception of the professional actors were summarized by domain and compared between the test group and the control group. Favorable responses were defined as ratings of "agree" or "strongly agree." Subgroup analyses were conducted within each domain by professional actor age and gender (i.e., young man, young woman, older man, or older woman). Adjusted analyses were not performed due to randomization. Statistical comparisons were conducted using Wilcoxon signed-rank tests for continuous variables and chi-square tests for categorical variables. Analyses were conducted using R (R Core Team, 2017).

\section{RESULTS}

A total of 4,800 participants were recruited to fill out surveys in response to the mild-to-moderate or moderate-to-severe TD videos ( $n=2,400$ each), with no overlap between groups (Supplementary Fig. 1; available online). In each group, 800 participants completed 1 of 3 surveys (either employment, dating, or friendship), evaluating actors either with or without TD. In the survey groups, each professional actor (i.e., younger and older man, younger and older woman) was seen by 200 participants who were randomized $1: 1$ to be assigned to either the test group or the control group (each video was viewed by 100 participants).

\section{Participant Characteristics}

In general, participant characteristics were balanced between the test and control groups for each survey in the mild-to-moderate and moderate-to-severe TD analyses after stratifying for professional actor characteristics (i.e., age, gender) or across videos of different professional actors (Supplementary Table 2; available online).

In the mild-to-moderate TD sample, test group participants who viewed videos of the younger man for the employment survey had significantly more experience in hiring non-client-facing position types and control group participants who viewed the video of the younger woman had more experience hiring for client-facing positions. For the dating and friendship surveys, there were some differences in age and gender composition of the groups as participants were assigned to videos based on age and 
sexual orientation.

In the moderate-to-severe TD sample, test group participants who viewed videos of the older man for the em- ployment survey had more experience than in the control group in hiring for positions that do not involve facing customers. Most characteristics were balanced between

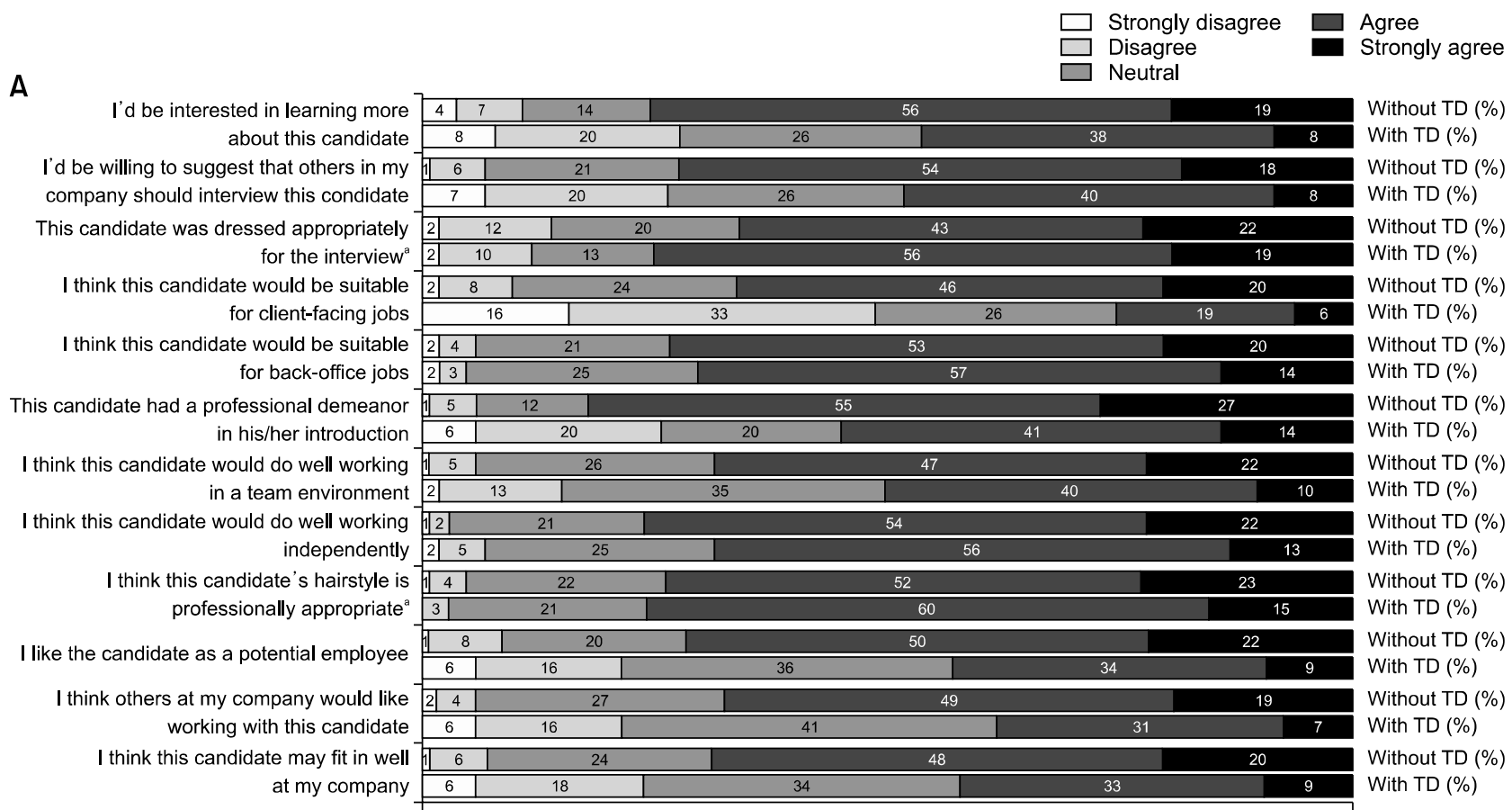

B

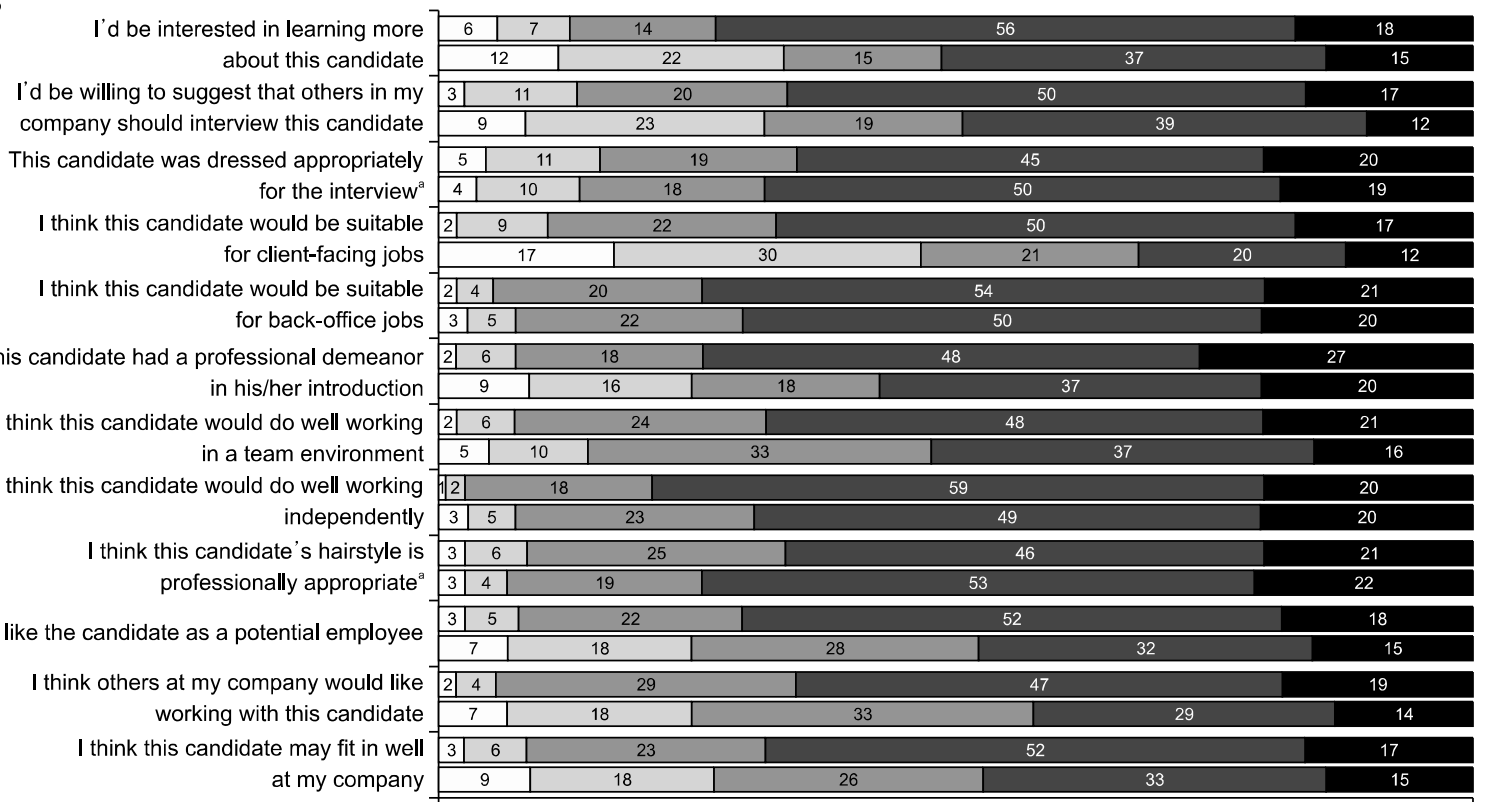

Without TD (\%) With TD (\%) Without TD (\%) With TD (\%) Without TD (\%) With TD (\%) Without TD (\%) With TD (\%) Without TD (\%) With TD (\%) Without TD (\%) With TD (\%) Without TD (\%) With TD (\%) Without TD (\%) With TD (\%) Without TD (\%) With TD (\%) Without TD (\%) With TD (\%) Without TD (\%) With TD (\%) Without TD (\%) With TD (\%)

Fig. 1. Overall summary of employment domain results, stratified by videos showing individuals with or without (A) mild-to-moderate TD or (B) moderate-to-severe TD movements. Distribution of participants' survey responses in the employment domain, stratified by videos showing people without TD (control group) and with TD (test group). Participants were able to respond using 1 of the following ratings: 1 ) strongly disagree, 2) disagree, 3) neutral, 4) agree, 5) strongly agree.

TD, tardive dyskinesia.

${ }^{a}$ These questions were included in order to conceal the study objectives from the participants. There are expected to be no significant differences between the videos showing people with and without TD for these questions. 
the test and control groups for the dating and friendship surveys; however, some differences were seen based on assignment of the videos to participants based on their age and sexual orientation. In the dating survey, the test group who saw TD simulated by an older woman was significantly older and included a higher percentage of Whites than the corresponding control group. In the friendship survey, the test group who saw TD simulated by a young man had a higher percentage of men than the corresponding control group. Additionally, the test groups who saw TD simulated by a young man or older man had different frequencies of attending social events than the corresponding control groups.

\section{Employment Survey}

The percentage of participants who agreed with statements in the employment survey was lower in the test group than in the control group in both the mild-to-mod- erate and moderate-to-severe TD samples (Fig. 1, Table 1), suggesting that participants had a more negative perception of the employment potential of a person showing TD movements than of one who does not. For the mild-tomoderate TD analyses, significantly fewer participants in the test group versus the control group were interested in learning more about the candidate (45.8\% vs. $75.3 \%$; $p<0.001$ ), were willing to suggest others in the company to interview the candidate $(47.8 \%$ vs. $71.3 \% ; p<0.001$ ), agreed that the candidate would be suitable for client-facing jobs (24.8\% vs. $65.8 \%$; $p<0.001)$, thought the candidate had a professional demeanor in his/her introduction (54.5\% vs. $82.0 \% ; p<0.001)$, felt that the candidate would do well working either in a team $(49.5 \%$ vs. $68.3 \%$; $p<0.001)$ or independently (68.8\% vs. $76.8 \%$; $p<0.05)$, liked the candidate as a potential employee $(42.8 \%$ vs. $72.0 \% ; p<0.001)$, thought that coworkers would like to work with this candidate $(38.0 \%$ vs. $67.5 \% ; p<0.001)$,

Table 1. Participant responses (strongly agree/agree) stratified by employment domain videos showing Individuals with/without TD

\begin{tabular}{|c|c|c|c|c|c|c|}
\hline \multirow[b]{2}{*}{ Survey questions } & \multicolumn{3}{|c|}{ Mild-to-moderate TD } & \multicolumn{3}{|c|}{ Moderate-to-severe TD } \\
\hline & $\begin{array}{l}\text { Actors without } \\
\text { TD symptoms } \\
(\mathrm{n}=400)\end{array}$ & $\begin{array}{l}\text { Actors with } \\
\text { TD symptoms } \\
(\mathrm{n}=400)\end{array}$ & $p$ value & $\begin{array}{l}\text { Actors without } \\
\text { TD symptoms } \\
(n=400)\end{array}$ & $\begin{array}{l}\text { Actors with } \\
\text { TD symptoms } \\
(\mathrm{n}=400)\end{array}$ & $p$ value \\
\hline $\begin{array}{l}\text { l'd be interested in learning more about this } \\
\text { candidate }\end{array}$ & $301(75.3)$ & $183(45.8)$ & $<0.001$ & $297(74.3)$ & $205(51.3)$ & $<0.001$ \\
\hline $\begin{array}{l}\text { I'd be willing to suggest that others in my } \\
\text { company should interview this candidate }\end{array}$ & $285(71.3)$ & $191(47.8)$ & $<0.001$ & $265(66.3)$ & $200(50.0)$ & $<0.001$ \\
\hline $\begin{array}{l}\text { This candidate was dressed appropriately } \\
\text { for the interview }{ }^{\text {a }}\end{array}$ & $261(65.3)$ & $297(74.3)$ & $<0.01$ & $260(65.0)$ & $273(68.3)$ & 0.37 \\
\hline $\begin{array}{l}\text { I think this candidate would be suitable for } \\
\text { client-facing jobs }\end{array}$ & $263(65.8)$ & $99(24.8)$ & $<0.001$ & $268(67.0)$ & $129(32.3)$ & $<0.001$ \\
\hline $\begin{array}{l}\text { I think this candidate would be suitable for } \\
\text { back-office jobs }\end{array}$ & $292(73.0)$ & $284(71.0)$ & 0.58 & $300(75.0)$ & $281(70.3)$ & 0.15 \\
\hline $\begin{array}{l}\text { This candidate had a professional demeanor } \\
\text { in his/her introduction }\end{array}$ & $328(82.0)$ & $218(54.5)$ & $<0.001$ & $297(74.3)$ & $227(56.8)$ & $<0.001$ \\
\hline $\begin{array}{l}\text { I think this candidate would do well working } \\
\text { in a team environment }\end{array}$ & $273(68.3)$ & $198(49.5)$ & $<0.001$ & $278(69.5)$ & $211(52.8)$ & $<0.001$ \\
\hline $\begin{array}{l}\text { I think this candidate would do well working } \\
\text { independently }\end{array}$ & $307(76.8)$ & $275(68.8)$ & $<0.05$ & $314(78.5)$ & $277(69.3)$ & $<0.01$ \\
\hline $\begin{array}{l}\text { I think this candidate's hairstyle is } \\
\text { professionally appropriate }^{\text {a }}\end{array}$ & $297(74.3)$ & $302(75.5)$ & 0.74 & $267(66.8)$ & $299(74.8)$ & $<0.05$ \\
\hline I like the candidate as a potential employee & $288(72.0)$ & $171(42.8)$ & $<0.001$ & $280(70.0)$ & $189(47.3)$ & $<0.001$ \\
\hline $\begin{array}{l}\text { I think others at my company would like } \\
\text { working with this candidate }\end{array}$ & $270(67.5)$ & $152(38.0)$ & $<0.001$ & $263(65.8)$ & $170(42.5)$ & $<0.001$ \\
\hline $\begin{array}{l}\text { I think this candidate may fit in well at my } \\
\text { company }\end{array}$ & $274(68.5)$ & $167(41.8)$ & $<0.001$ & $276(69.0)$ & $188(47.0)$ & $<0.001$ \\
\hline
\end{tabular}

Values are presented as number (\%).

TD, tardive dyskinesia.

${ }^{a}$ These questions were included in order to conceal the study objectives from the participants. There are expected to be no significant differences between the videos showing people with and without TD for these questions. Statistical significance was assessed by chi-square tests; $p$ values of $<0.05$ were considered significant. 


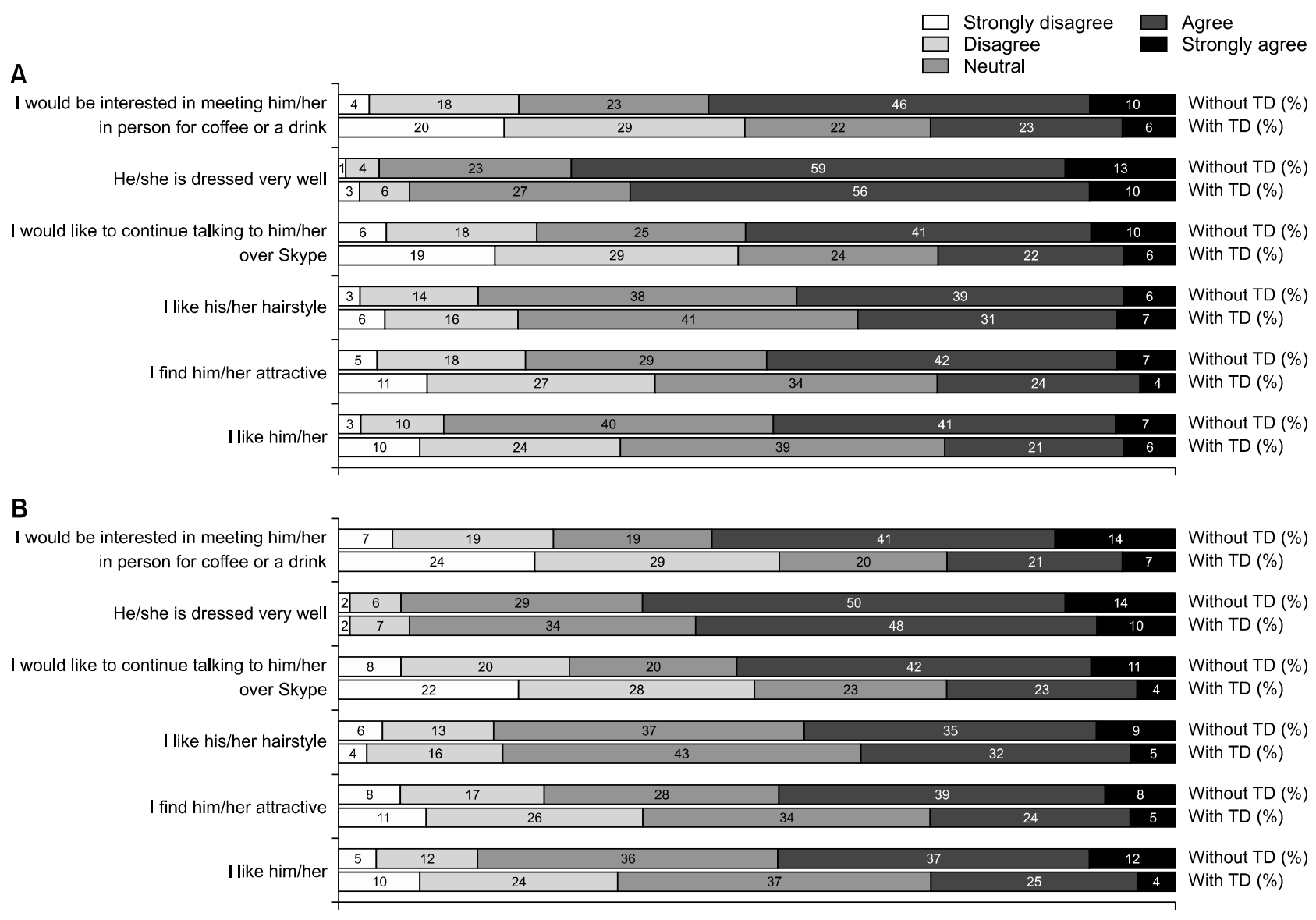

Fig. 2. Overall summary of dating domain results, stratified by videos showing individuals with or without (A) mild-to-moderate TD or (B) moderate-to-severe TD movements. Distribution of participants' survey responses in the dating domain, stratified by videos showing people without TD (control group) and with TD (test group). Participants were able to respond using 1 of the following ratings: 1) strongly disagree, 2) disagree, 3) neutral, 4) agree, 5) strongly agree.

TD, tardive dyskinesia.

or thought the candidate would fit in well at the company $(41.8 \%$ vs. $68.5 \% ; p<0.001)$. Similarly, significantly fewer participants in the test groups reported a positive view of the employment potential of persons showing moderate-to-severe movements of TD (Fig. 1B, Table 1). There was no significant difference between the test and control groups for patients with mild-to-moderate TD ( $p=$ $0.58)$ or moderate-to-severe TD $(p=0.15)$ when rating the candidate's suitability for back-office jobs.

Similar trends in survey responses were observed in subgroup analyses by professional actor as in the overall group for both mild-to-moderate and moderate-to-severe TD. Only 1 of the concealing questions asked of the mild-to-moderate TD group (i.e., whether the candidate was dressed appropriately for the interview) had a statistically significant difference in responses between the test and control groups $(p<0.01)$. For the moderate-to-severe TD group, the impact of TD was smaller for participants who saw the videos of the young man, with no significant difference in the percentage of participants who agreed with 8 (including the 2 concealing questions) out of 12 questions between the 2 groups.

\section{Dating Survey}

The ratings of agreement levels with the statements in the dating survey were lower in the test group than in the control group in both the mild-to-moderate and moderate-to-severe TD analyses (Fig. 2A, Table 2), suggesting that participants had a more negative perception of the romantic potential of people showing TD movements than of those who did not. For the mild-to-moderate TD analyses, a significantly lower proportion of participants in the 
Table 2. Participant responses (strongly agree/agree) stratified by dating and friendship domain videos showing individuals with/without TD

\begin{tabular}{|c|c|c|c|c|c|c|}
\hline \multirow[b]{2}{*}{ Survey questions } & \multicolumn{3}{|c|}{ Mild-to-moderate TD } & \multicolumn{3}{|c|}{ Moderate-to-severe TD } \\
\hline & $\begin{array}{c}\text { Actors without } \\
\text { TD symptoms } \\
(n=400)\end{array}$ & $\begin{array}{l}\text { Actors with } \\
\text { TD symptoms } \\
(\mathrm{n}=400)\end{array}$ & $p$ value & $\begin{array}{c}\text { Actors without } \\
\text { TD symptoms } \\
(\mathrm{n}=400)\end{array}$ & $\begin{array}{l}\text { Actors with } \\
\text { TD symptoms } \\
(\mathrm{n}=400)\end{array}$ & $p$ value \\
\hline \multicolumn{7}{|l|}{ Survey questions in the dating domain } \\
\hline $\begin{array}{l}\text { I would be interested in meeting him/her } \\
\text { in person for coffee or a drink }\end{array}$ & $220(55.0)$ & $116(29.0)$ & $<0.001$ & $219(54.8)$ & $110(27.5)$ & $<0.001$ \\
\hline $\mathrm{He} /$ she is dressed very well ${ }^{\mathrm{a}}$ & $289(72.3)$ & $260(65.0)$ & $<0.05$ & $255(63.8)$ & $230(57.5)$ & 0.08 \\
\hline $\begin{array}{l}\text { I would like to continue talking to him/her } \\
\text { over Skype }\end{array}$ & $205(51.3)$ & $112(28.0)$ & $<0.001$ & $210(52.5)$ & $110(27.5)$ & $<0.001$ \\
\hline I like his/her hairstyle ${ }^{\mathrm{a}}$ & $179(44.8)$ & $149(37.3)$ & $<0.05$ & $175(43.8)$ & $150(37.5)$ & 0.08 \\
\hline I find him/her attractive & $194(48.5)$ & $112(28.0)$ & $<0.001$ & $190(47.5)$ & $115(28.8)$ & $<0.001$ \\
\hline I like him/her & $189(47.3)$ & $108(27.0)$ & $<0.001$ & $194(48.5)$ & $118(29.5)$ & $<0.001$ \\
\hline \multicolumn{7}{|l|}{ Survey questions in the friendship domain } \\
\hline He/she seems to be an interesting person & $228(57.0)$ & $176(44.0)$ & $<0.001$ & $263(65.8)$ & $188(47.0)$ & $<0.001$ \\
\hline $\mathrm{He} /$ she is dressed very well ${ }^{\mathrm{a}}$ & $265(66.3)$ & $244(61.0)$ & 0.14 & $251(62.8)$ & $250(62.5)$ & 1.00 \\
\hline $\mathrm{He} /$ she seems friendly & $335(83.8)$ & $308(77.0)$ & $<0.05$ & $345(86.3)$ & $326(81.5)$ & 0.08 \\
\hline $\begin{array}{l}\text { I would consider meeting up with him/her } \\
\text { once he/she moves here }\end{array}$ & $253(63.3)$ & $209(52.3)$ & $<0.01$ & $261(65.3)$ & $220(55.0)$ & $<0.01$ \\
\hline I like his/her hairstyle ${ }^{\mathrm{a}}$ & $130(32.5)$ & $131(30.3)$ & 0.54 & $147(36.8)$ & $145(36.3)$ & 0.94 \\
\hline $\begin{array}{l}\text { I would be open to introducing him/her to } \\
\text { my friends once he/she moves here }\end{array}$ & $229(57.3)$ & $176(44.0)$ & $<0.001$ & $237(59.3)$ & $195(48.8)$ & $<0.01$ \\
\hline $\begin{array}{l}\text { I would be interested in becoming friends } \\
\text { with him/her }\end{array}$ & $203(50.8)$ & $154(38.5)$ & $<0.001$ & 239 (59.8) & $173(43.3)$ & $<0.001$ \\
\hline
\end{tabular}

Values are presented as number (\%).

TD, tardive dyskinesia.

${ }^{a}$ These questions were included in order to conceal the study objectives from the participants. There are expected to be no significant differences between the videos showing people with and without TD for these questions. Statistical significance was assessed by chi-square tests; $p$ values of $<0.05$ were considered significant.

test group versus the control group agreed they would like to continue talking to the person over Skype (28.0\% vs. $51.3 \% ; p<0.001)$, found him/her attractive (28.0\% vs. $48.5 \%$; $p<0.001)$, or were interested in meeting the person for a coffee/drink (29.0\% vs. $55.0 \%$; $p<0.001)$. Similar results were obtained in the moderate-to-severe TD analyses (Fig. 2B, Table 2).

In the subgroup analyses by professional actor, trends were generally similar to those in the overall group for both the mild-to-moderate and moderate-to-severe TD groups. For the mild-to-moderate TD group, significantly fewer people agreed with the 2 concealing statements (i.e., the person is dressed very well, and I like the person's hairstyle) in the test group than in the control group ( $p<0.05$ ). For both the mild-to-moderate and moderate-to-severe TD groups, the impact of TD was smaller for participants who saw the videos of the young woman actor, with no significant differences between the test and control groups on all questions (except for 1 question in the mild-to-moderate TD group). For the moderate-to-severe TD group, the social impact of TD symptoms simulated by professional actors tended to be greater in the videos with the older woman actor than in the other videos, which may have influenced the responses. The percentage of participants who would be interested in meeting the older woman for coffee or a drink was significantly lower in the test group versus the control group (23.0\% vs. $63.0 \% ; p<0.001$ ); similarly, fewer participants in the test group versus the control group expressed interest in her $(23.0 \%$ vs. $60.0 \%$; $p<0.001)$.

\section{Friendship Survey}

Ratings of agreement with all questions on the friendship survey were lower in the test group than in the control group in both the mild-to-moderate and moderate-tosevere TD groups (Fig. 3, Table 2), suggesting that participants had a more negative perception of the friendship potential of people showing TD movements than of those who did not. For the mild-to-moderate TD analyses, fewer participants in the test group versus the control group said 


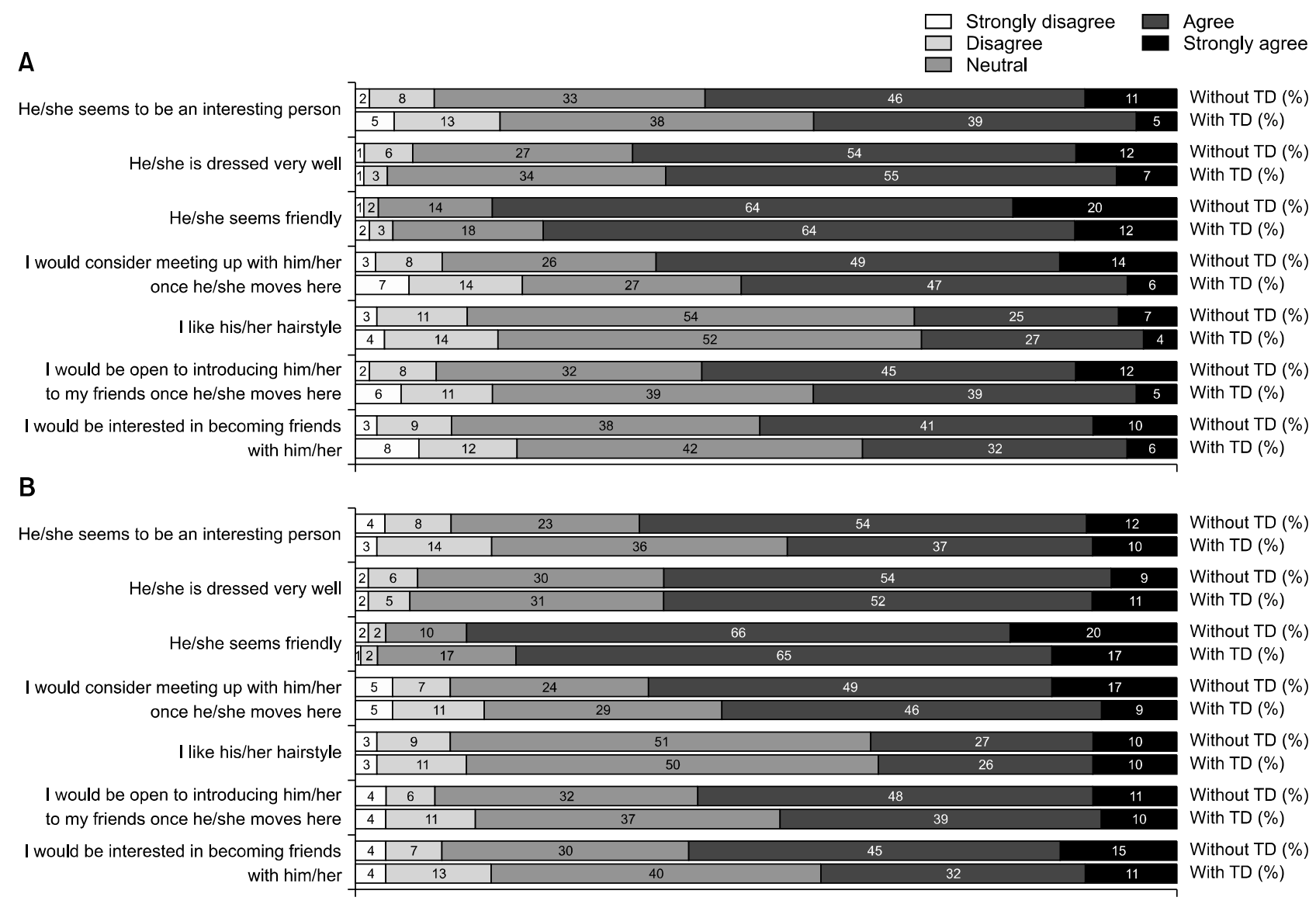

Fig. 3. Overall summary of friendship domain results, stratified by videos showing individuals with or without (A) mild-to-moderate TD or (B) moderate-to-severe TD movements. Distribution of participants' survey responses in the friendship domain, stratified by videos showing people without TD (control group) and with TD (test group). Participants were able to respond using 1 of the following ratings: 1) strongly disagree, 2) disagree, 3) neutral, 4) agree, 5) strongly agree.

TD, tardive dyskinesia.

they would consider meeting up with the candidate $(52.3 \%$ vs. $63.3 \% ; p<0.01$ ) or would introduce the candidate to friends $(44.0 \%$ vs. $57.3 \% ; p<0.001)$. Significantly fewer participants in the test group rated the candidate as interesting $(44.0 \%$ vs. $57.0 \% ; p<0.001)$ or indicated interest in becoming friends ( $38.5 \%$ vs. $50.8 \% ; p<0.001$ ). Results were similar in the moderate-to-severe TD analyses (Fig. 3B, Table 2).

In the subgroup analyses by actor for the mild-to-moderate TD group, similar trends were observed as in the overall group, except for the group that viewed the video with the younger female actor. In this subgroup, none of the differences in ratings of agreement with the statements were statistically significant between the test and control groups. In the subgroup analyses by professional actor for the moderate-to-severe TD group, the social impact of TD simulated by professional actors tended to be smaller for participants who saw the videos of the young woman and young man; there were no significant differences between the test and control groups for those videos on all questions.

\section{DISCUSSION}

Previous observations suggested that the social stigma associated with TD, especially with orofacial movements, could have substantial negative social, economic, and psychologic consequences $[15,17,19-22,30,31]$. Furthermore, people with TD have described that unwanted social attention, a feeling of embarrassment, and social isolation due to TD symptoms are among the most debilitating aspects of living with the condition regardless of the severity of the TD movements [25,32]. However, the social stigma of both mild-to-moderate and moderate-to-severe TD movements on people's lives has not been systemati- 
cally evaluated from the point of view of outside observers in professional and social situations. Regardless of the patient's awareness, insight, and discomfort, the impact of TD on their social and professional success may also depend on the perspective, prejudice, and bias of others. To our knowledge, this is the first study to quantitatively evaluate the potential stigma faced by people exhibiting both mild-to-moderate and moderate-to-severe TD movements in both professional and social settings based on the response of lay observers. Responses to employment, dating, and friendship surveys suggest that people exhibiting abnormal TD movements are significantly less likely to advance in a job interview and are less likely to be considered as a potential romantic partner or as a new friend than people without TD, whether or not they are personally aware of the disorder. These findings were generally consistent regardless of symptom severity.

There have been some efforts to understand the impact of TD movements in professional settings. In a previous study, students evaluated 2 job candidates: one with and one without TD. The result was a negative effect on hiring candidacy due to TD symptoms [27]. However, that study was conducted using different people for the TD and nonTD symptoms, and thus did not control for other characteristics (e.g., confounding effects of age, gender, psychiatric symptoms) that could account for these differences, which limits the interpretation of the findings. In addition, that study did not assess the social impact of TD on other areas of patients' lives, such as their friendships or romantic lives. Other studies addressing the impact of facial abnormalities on employment showed reactions by the general population that were consistent with our findings. One study by Madera et al. found that facially stigmatized applicants received lower ratings by hiring managers than those without [33]. Another study by Dey et al. [34] used images of different people with physical facial lesions to show the impact of stigmatization on social comfort. Although these studies investigated the impact of abnormal facial features, the findings have limited application to the stigma associated with TD, as applicants were stigmatized by anatomic facial lesions rather than involuntary abnormal movements. Similarly, previous studies have demonstrated that patients with Parkinson's disease, another movement disorder, experience stigma due to their movement and communication difficulties, which negatively impacts their quality of life and social relation- ships $[35,36]$.

The integrated, mixed methods used in our study involved both qualitative interviews with patients and quantitative measurement of stigma by the general population toward people with TD, with separate analyses conducted to determine whether perceptions are influenced by the severity of TD movements. The design strengthens the study, as the questions included in the quantitative survey were informed by the interviews and are therefore more likely to matter to patients. To encourage honesty from participants with respect to the sensitive topics of mental health, behavioral disorders, and social stigma, this study used a digital portal for greater anonymity. Furthermore, people with TD were represented by professional actors whose simulated TD movements were reviewed by experienced, practicing physicians and verified for authenticity. The scores for similarity of TD movements portrayed by professional actors to real-life TD movements among all domains generally indicated the applicability of survey responses to people with mild-tomoderate and moderate-to-severe TD movements. The use of professional actors allowed the generation of 2 very similar videos with and without the presence of simulated TD movements in the same person, thereby minimizing confounding effects in a direct comparison, with abnormal movements as the only variable differing between test and control videos. A similar methodology could be used to assess stigmatization in other movement disorders, broadening these findings.

Although this study provides evidence for stigma associated with TD, it may still be over- or underestimated due to some limitations of the surveys. This study assessed participant perceptions of a simulated TD patient based on a 30-second video and therefore only evaluated the impact of TD on first impressions. People typically gather more information about a person over time (e.g., from additional interview questions or longer conversations in a social setting) that may change their perception. However, studies have shown that the first impression in both social and professional settings may already diminish interest in a person, and people may not be willing to spend more time gathering additional information [37-39]. This is an indication that people were subjected to some stigma even with mild-to-moderate TD movements, which they may not even be aware of. Thus, increasing awareness and understanding of someone's condition may have a 
crucial impact on people's attitude toward someone that exhibits TD movements. Furthermore, it is possible that people's true actions may be different from their stated potential actions in the survey. It is possible that those viewing videos of TD simulated by professional actors suspected the purpose of the study and biased their responses. To minimize this possibility, several concealing questions were included in each domain to help mask the underlying study objective (e.g., in the employment domain, that the interviewee's clothing was appropriate for the job). In general, responses to these concealing questions were not different between the test group and the control group, suggesting that participants were not biased and supporting the hypothesis that the stigma experienced by people with TD is limited to areas of social interaction and does not spill over into other areas such as visual appearance.

With the increasing prevalence of TD and the continued increased prescribing of antipsychotics for broader patient populations and off-label use, it is crucial to understand the impact of TD movements on patients' social and professional lives. This depends in part on the perceptions of outside observers. Here we show evidence that people with both mild-to-moderate and moderate-to-severe abnormal movements experience profound negative social bias and consequences, which can manifest in distinct ways that affect multiple aspects of their lives. This study highlights the importance of broadening the ways in which the impact of TD is measured and how this can be leveraged to avoid delays in diagnosis. It also underscores the urgent need for effective therapies that mitigate TD symptoms, while allowing patients to manage their underlying psychiatric disorders to prevent relapse.

\section{- Funding}

This study was funded by Teva Pharmaceuticals, Petach Tikva, Israel.

\section{Acknowledgments}

We thank Arjun Menon, PhD, and Dana Meyen, PhD (Chameleon Communications International with funding from Teva Pharmaceuticals), and Caryn Gordon, PharmD, and Shravanthi Chidambaram, PhD (Cello Health Communications/MedErgy with funding from Teva Pharmaceuticals), for editorial assistance in the preparation of this report; and Eric $\mathrm{Wu}, \mathrm{PhD}$, Anjali Oza, $\mathrm{PhD}$,
Mo Zhou, PhD, and Stephanie Bousleiman, BS, from Analysis Group and Zachary Predmore, BA, from Johns Hopkins University for their contributions to study design and execution.

\section{- Conflicts of Interest}

Rajeev Ayyagari: Employee of Analysis Group, Inc. Debbie Goldschmidt: Employee of Analysis Group, Inc. Fan Mu: Employee of Analysis Group, Inc. Stanley N. Caroff: Consultant for Teva Pharmaceuticals, Neurocrine Biosciences, Osmotica Pharmaceuticals, Dispersol Technologies; research grant from Neurocrine Biosciences. Benjamin Carroll: Employee of Teva Branded Pharmaceutical Products R\&D, Inc.

\section{Author Contributions}

Conceptualization: Rajeev Ayyagari, Debbie Goldschmidt, Fan Mu, Stanley N. Caroff, Benjamin Carroll. Data acquisition: Rajeev Ayyagari, Debbie Goldschmidt, Fan Mu, Stanley N. Caroff, Benjamin Carroll. Formal analysis: Rajeev Ayyagari, Debbie Goldschmidt, Fan Mu. Supervision: Rajeev Ayyagari, Benjamin Carroll. Writing-original draft: Rajeev Ayyagari, Debbie Goldschmidt, Fan Mu, Stanley N. Caroff, Benjamin Carroll. Writing - review \& editing: Rajeev Ayyagari, Debbie Goldschmidt, Fan Mu, Stanley N. Caroff, Benjamin Carroll.

\section{ORCID}

Rajeev Ayyagari https://orcid.org/0000-0003-0870-2309

Debbie Goldschmidt https://orcid.org/0000-0002-8334-2211

Fan $\mathrm{Mu} \quad$ https://orcid.org/0000-0003-0252-0387

Stanley N. Caroff https://orcid.org/0000-0003-2840-4763

Benjamin Carroll https://orcid.org/0000-0001-6076-1643

\section{REFERENCES}

1. Buchanan RW, Kreyenbuhl J, Kelly DL, Noel JM, Boggs DL, Fischer BA, et al. The 2009 schizophrenia PORT psychopharmacological treatment recommendations and summary statements. Schizophr Bull 2010;36:71-93.

2. Kemp DE. Managing the side effects associated with commonly used treatments for bipolar depression. J Affect Disord 2014; 169 Supp/ 1:S34-S44.

3. Dea L, Tran J, Tsu L, Gutierrez MA. Management of bipolar disorder. US Pharm 2016;41:34-37.

4. Marder SR, Essock SM, Miller AL, Buchanan RW, Casey DE, Davis JM, et al. Physical health monitoring of patients with schizophrenia. Am J Psychiatry 2004;161:1334-1349.

5. Caroff SN, Campbell EC. Drug-induced extrapyramidal syn- 
dromes: implications for contemporary practice. Psychiatr Clin North Am 2016;39:391-411.

6. Correll CU, Detraux J, De Lepeleire J, De Hert M. Effects of antipsychotics, antidepressants and mood stabilizers on risk for physical diseases in people with schizophrenia, depression and bipolar disorder. World Psychiatry 2015;14:119-136.

7. Cornett EM, Novitch M, Kaye AD, Kata V, Kaye AM. Medicationinduced tardive dyskinesia: a review and update. Ochsner J 2017;17:162-174.

8. Okkels N, Vernal DL, Jensen SO, McGrath JJ, Nielsen RE. Changes in the diagnosed incidence of early onset schizophrenia over four decades. Acta Psychiatr Scand 2013;127: 62-68.

9. Maglione M, Maher AR, Hu J, Wang Z, Shanman R, Shekelle PG, et al. Off-label use of atypical antipsychotics: an update. Rockville:Agency for Healthcare Research and Quality (US); 2011.

10. National Center for Advancing Translational Sciences. Tardive dyskinesia [Internet]. Gaithersburg: National Center for Advancing Translational Sciences; 2014 [cited at 2021 Jun 9]. Available from: https://rarediseases.info.nih.gov/diseases/7732/ tardive-dyskinesia.

11. Carbon M, Hsieh CH, Kane JM, Correll CU. Tardive dyskinesia prevalence in the period of second-generation antipsychotic use: a meta-analysis. I Clin Psychiatry 2017;78: e264-e278.

12. Cunningham Owens DG. A guide to the extrapyramidal sideeffects of antipsychotic drugs. 2nd ed. Cambridge:Cambridge University Press;2014.

13. Tarsy D. Neuroleptic-induced extrapyramidal reactions: classification, description, and diagnosis. Clin Neuropharmacol 1983;6 Supp/ 1:S9-S26.

14. Caroff SN, Ungvari GS, Cunningham Owens DG. Historical perspectives on tardive dyskinesia. J Neurol Sci 2018;389:4-9.

15. Ascher-Svanum H, Zhu B, Faries D, Peng X, Kinon BJ, Tohen M. Tardive dyskinesia and the 3-year course of schizophrenia: results from a large, prospective, naturalistic study. I Clin Psychiatry 2008;69:1580-1588.

16. Abdallah C, Cohen Cl, Sanchez-Almira M, Reyes P, Ramirez P. Community integration and associated factors among older adults with schizophrenia. Psychiatr Serv 2009;60:1642-1648.

17. Sandyk R, Kay SR, Awerbuch GI. Subjective awareness of abnormal involuntary movements in schizophrenia. Int I Neurosci 1993;69:1-20.

18. Carroll B, Irwin DE. Health care resource utilization and costs for patients with tardive dyskinesia. J Manag Care Spec Pharm 2019;25:810-816.

19. Yassa R, Jones BD. Complications of tardive dyskinesia: a review. Psychosomatics 1985;26:305-307, 310, 312-313.

20. Yassa R. Functional impairment in tardive dyskinesia: medical and psychosocial dimensions. Acta Psychiatr Scand 1989;80: 64-67.

21. Browne S, Roe M, Lane A, Gervin M, Morris M, Kinsella A, et al. Quality of life in schizophrenia: relationship to sociodemographic factors, symptomatology and tardive dyskinesia. Acta Psychiatr Scand 1996;94:118-124.

22. Strassnig M, Rosenfeld A, Harvey PD. Tardive dyskinesia: motor system impairments, cognition and everyday functioning. CNS Spectr 2018;23:370-377.

23. McEvoy J, Park T, Schilling T, Terasawa E, Ayyagari R, Carroll B. The burden of tardive dyskinesia secondary to antipsychotic medication use among patients with mental disorders. Curr Med Res Opin 2019;35:1205-1214.

24. Gharabawi GM, Bossie CA, Lasser RA, Turkoz I, Rodriguez S, Chouinard G. Abnormal Involuntary Movement Scale (AIMS) and Extrapyramidal Symptom Rating Scale (ESRS): cross-scale comparison in assessing tardive dyskinesia. Schizophr Res 2005; 77:119-128.

25. Bergman H, Walker DM, Nikolakopoulou A, Soares-Weiser $\mathrm{K}$, Adams CE. Systematic review of interventions for treating or preventing antipsychotic-induced tardive dyskinesia. Health Technol Assess 2017;21:1-218.

26. Dhir A, Schilling T, Abler V, Potluri R, Carroll B. Estimation of tardive dyskinesia incidence and prevalence in the United States. In: American Academy of Neurology Annual Meeting; Apr 22-28, 2017; Boston, USA.

27. Boumans CE, de Mooij KJ, Koch PA, van't Hof MA, Zitman FG. Is the social acceptability of psychiatric patients decreased by orofacial dyskinesia? Schizophr Bull 1994;20:339-344.

28. Anderson KE, Stamler D, Davis MD, Factor SA, Hauser RA, Isojärvi J, et al. Deutetrabenazine for treatment of involuntary movements in patients with tardive dyskinesia (AIM-TD): a double-blind, randomised, placebo-controlled, phase 3 trial. Lancet Psychiatry 2017:4:595-604.

29. Fernandez HH, Factor SA, Hauser RA, Jimenez-Shahed J, Ondo WG, Jarskog LF, et al. Randomized controlled trial of deutetrabenazine for tardive dyskinesia: the ARM-TD study. Neurology 2017;88:2003-2010.

30. Anusa AM, Thavarajah R, Nayak D, Joshua E, Rao UK, Ranganathan K. A study on drug-induced tardive dyskinesia: orofacial musculature involvement and patient's awareness. J Orofac Sci 2018;10:86-95.

31. Lerner PP, Miodownik C, Lerner V. Tardive dyskinesia (syndrome): current concept and modern approaches to its management. Psychiatry Clin Neurosci 2015;69:321-334.

32. Farber R, Sparta D, Gauthier M, Witherspoon B, O'Brien CF, Evans C. Tardive dyskinesia: patient and caregiver perspectives on signs, symptoms, and impact. In: Psych Congress Annual Meeting; Sep 16-19, 2017; New Orleans, USA.

33. Madera JM, Hebl MR. Discrimination against facially stigmatized applicants in interviews: an eye-tracking and face-toface investigation. J Appl Psychol 2012;97:317-330.

34. Dey JK, Ishii LE, Byrne PJ, Boahene KD, Ishii M. The social penalty of facial lesions: new evidence supporting high-quality reconstruction. JAMA Facial Plast Surg 2015;17:90-96.

35. Hemmesch AR, Tickle-Degnen L, Zebrowitz LA. The influ- 
ence of facial masking and sex on older adults' impressions of individuals with Parkinson's disease. Psychol Aging 2009;24: 542-549.

36. Ma HI, Saint-Hilaire M, Thomas CA, Tickle-Degnen L. Stigma as a key determinant of health-related quality of life in Parkinson's disease. Qual Life Res 2016;25:3037-3045.

37. South Palomares JK, Sutherland CAM, Young AW. Facial first impressions and partner preference models: comparable or distinct underlying structures? Br J Psychol 2018; 109:538-563.

38. Willis J, Todorov A. First impressions: making up your mind after a 100-ms exposure to a face. Psychol Sci 2006;17:592-598.

39. Dougherty TW, Turban DB, Callender JC. Confirming first impressions in the employment interview: a field study of interviewer behavior. J Appl Psychol 1994;79:659-665. 